\title{
Bioavailability of perfluorooctane sulfonate (PFOS) and perfluorooctanoic acid (PFOA) in biosolids-amended soils to earthworms (Eisenia fetida)
}

\author{
Bei Wen ${ }^{\mathrm{a}, *}$, Hongna Zhang ${ }^{\mathrm{a}}$, Longfei $\mathrm{Li}^{\mathrm{a}}{ }$, Xiaoyu Hu ${ }^{\mathrm{b}}$, Yu Liu ${ }^{\mathrm{a}}$, Xiao-quan Shan ${ }^{\mathrm{a}}$, Shuzhen Zhang ${ }^{\mathrm{a}}$ \\ a State Key Laboratory of Environmental Chemistry and Ecotoxicology, Research Center for Eco-Environmental Sciences, Chinese Academy of Sciences, Beijing 100085, China \\ ${ }^{\mathrm{b}}$ Beijing Center for Disease Prevention and Control, Beijing 100031, China
}

\section{H I G H L I G H T S}

- Bioavailability of PFOS and PFOA by earthworm in biosolids-amended soils was studied.

- The uptake and elimination kinetics fit a one-compartment first-order kinetic model.

- PFOS displayed higher $k_{\mathrm{u}}$, lower $k_{\mathrm{e}}$, and longer $t_{\mathrm{ss}}$ than those of PFOA.

- The bioaccumulation factors and $t_{\mathrm{ss}}$ decreased with soil concentrations increasing.

- Soil concentration and OM contents accounted for earthworm bioavailability.

\section{A R T I C L E I N F O}

\section{Article history:}

Received 16 April 2014

Received in revised form 28 July 2014

Accepted 2 August 2014

Available online 16 November 2014

Handling Editor: Myrto Petreas

\section{Keywords:}

Earthworm

Uptake

Elimination

Perfluorooctane sulfonate

Perfluorooctanoic acid

Biosolid

\begin{abstract}
A B S T R A C T
The bioavailability of perfluorooctane sulfonate (PFOS) and perfluorooctanoic acid (PFOA) in seven biosolids-amended soils without any additionally spiking to earthworms (Eisenia fetida) was studied. The uptake and elimination kinetics of PFOS and PFOA fit a one-compartment first-order kinetic model. PFOS displayed higher uptake and lower elimination rate coefficients, and longer time to reach steady-state $\left(t_{\mathrm{ss}}\right)$ than those of PFOA. The bioaccumulation factors (BAFs) of PFOS and PFOA ranged 1.54-4.12 and $0.52-1.34 \mathrm{~g}_{\text {soil }} \mathrm{g}_{\text {worm }}^{-1}$, respectively. The BAFs and $t_{\mathrm{ss}}$ decreased with increasing concentrations of PFOS and PFOA in soils. Stepwise multiple regression analysis was used to elucidate the bioavailability of PFOS and PFOA. The results showed that the total concentrations of PFOS and PFOA, and organic matter (OM) contents in soils explained $87.2 \%$ and $91.3 \%$ of the variation in bioavailable PFOS and PFOA, respectively. PFOS and PFOA concentrations exhibited positive influence and OM contents showed the negative influence on the accumulation of PFOS and PFOA in earthworms. Soil pH and clay contents played relatively unimportant role in PFOS and PFOA bioavailability.
\end{abstract}

(c) 2014 Elsevier Ltd. All rights reserved.

\section{Introduction}

Perfluoroalkyl substances (PFASs) have been used for over the past 60 years in an increasing variety of consumer and industrial products, such as fire-retardant foams, inks, paper, lubricants, cosmetics, upholstery and so on. As a result of the large production and wide application, PFASs are broadly present in the environment. Within the PFAS group, perfluorooctane sulfonate (PFOS) and perfluorooctanoic acid (PFOA) are the most commonly used and found compounds (Hu et al., 2011). They have garnered intense scientific and regulatory interests due to their

\footnotetext{
* Corresponding author. Tel.: +86 10 62849329; fax: +86 1062923563 .

E-mail address: bwen@rcees.ac.cn (B. Wen).
}

extraordinary persistence, bioaccumulation tendencies and potential toxicological effects. So far, PFOS and PFOA have been found in atmosphere (Li et al., 2011), soil (Yoo et al., 2010), surface water (Hu et al., 2011), sediment (Higgins et al., 2005), and biota (Müller et al., 2011). They were also present in the serum of wildlife and humans and could be biomagnified in terrestrial and aquatic food webs (Müller et al., 2011; Houde et al., 2011).

Sewage sludge is an important sink of PFOS and PFOA (Higgins et al., 2005; Sun et al., 2011). The land application of treated sewage sludge (biosolids) is the option favored internationally for sludge management as it contributes to improve soil fertility and properties (Clarke and Smith, 2011). However, the use of biosolids as fertilizer in agriculture can cause contamination of 
PFASs in soils (Yoo et al., 2010; Washington et al., 2010; Sepulvado et al., 2011; Wen et al., 2014).

Organisms are liable to take up organic contaminants and may accumulate high level of PFASs when they live in contaminated soil environment. A few studies have been conducted and revealed plant uptake of PFASs from soils (Yoo et al., 2011; Wen et al., 2014; Zhao et al., 2014). Organic matter (OM) in soil was reported to play an important role in limiting plant uptake of PFASs. Earthworms comprise the largest part of the soil fauna biomass and are able to accumulate various organic contaminants, including polybrominated diphenyl ethers (PBDEs, Liang et al., 2010), polycyclic aromatic hydrocarbons (PAHs, Gomez-Eyles et al., 2011), and antimicrobials (Wen et al., 2011), etc. Accumulation of organic contaminants implies a risk to not only earthworm populations but also many vertebrate species feeding on earthworms. So far information about the accumulation of PFASs by earthworms from soil is quite limited. The work of Zhao et al. (2013) is perhaps the only available research on earthworm uptake of PFASs from artificially-contaminated soil, which suggested that the biota-to-soil accumulation factors (BSAFs) increased with perfluorinated carbon chain length. However, artificially polluted soils do not reflect the actual behavior of weathered PFASs in field soils. Moreover, it is still unknown how soil properties affect the accumulation of PFASs in earthworms.

In this study, seven soil samples collected from biosolidsamended fields without any additionally spiking were used to investigate the bioavailability of PFASs by earthworm (Eisenia fetida) in the laboratory. The objectives of the study were (i) to evaluate the uptake and elimination kinetics of PFOS and PFOA in earthworms and (ii) to investigate the key factors controlling the bioavailability of PFOS and PFOA in soils.

\section{Materials and methods}

\subsection{Materials}

Purities of all of the analytical standards were $\geqslant 95 \%$. Potassium PFOS and PFOA were obtained from Sigma (St. Louis, MO). ${ }^{13} \mathrm{C}_{4}$-PFOS and ${ }^{13} \mathrm{C}_{4}$-PFOA purchased from Wellington Laboratories (Guelph, Canada) were used as-received. HPLC-grade methyl tert-butyl ether (MTBE), methanol (MeOH), and acetonitrile were purchased from Fisher Chemical (Firlawn, NJ, USA). Tetrabutylammonium hydrogen sulfate (TBAHS), sodium carbonate, sodium hydroxide and ammonium acetate were purchased from Aldrich Chemical (Milwaukee, WI, USA). Oasis ${ }^{\circledR}$ WAX (6 cc, $150 \mathrm{mg}$, $30 \mu \mathrm{m}$ ) solid-phase extraction (SPE) cartridges were purchased from Waters (Milford, MA). Distilled water was used throughout the experimental work.

\subsection{Soil sample collection and preparation}

Seven soil samples (Nos. 1-7) were collected from surface layer $(0-20 \mathrm{~cm})$ of biosolids-amended agricultural fields in Changping, Beijing $\left(40^{\circ} 13^{\prime} \mathrm{N}, 116^{\circ} 15^{\prime} \mathrm{E}\right)$ and Dezhou, Shandong province $\left(37^{\circ} 20^{\prime} \mathrm{N}, 116^{\circ} 38^{\prime} \mathrm{E}\right)$. Soils were classified according to the American Classification System. The orders of soils in Changping and Dezhou were Mollisols. Uncontaminated soil was collected from an experimental field at Beijing Academy of Agriculture and Forestry Sciences. The soils were air-dried, ground and screened through a methanol-washed, 2-mm stainless-steel sieve to remove stones, plant roots, and other large particles. PFOS and PFOA in soils were determined.

Soil $\mathrm{pH}$ was measured in $\mathrm{CaCl}_{2}(0.01 \mathrm{M})$ at a soil to solution ratio of $1: 5(w: v)$. Cation-exchange capacity (CEC) was determined by the method of Rhoades (1982). Organic matter was determined by the Walkley-Black procedure (Nelson and Sommers, 1982). The selected soil properties and concentrations of PFOS and PFOA in the soils are given in Table S1.

\subsection{Earthworms}

Mature (clitellate) earthworms were purchased from the Agricultural University of China (Beijing, China) and maintained in moistened uncontaminated soil (40\% water holding capacity) at $22 \pm 2{ }^{\circ} \mathrm{C}$ for at least two weeks before use. The wet weight of an individual earthworm was on average $350 \pm 20 \mathrm{mg}(n=30)$. Before the experiment was commenced, earthworms were allowed to depurate for $24 \mathrm{~h}$ on moist filter paper. Earthworms were kept in the dark during all tests. The PFOS and PFOA in earthworm were determined.

\subsection{Uptake kinetics of PFOS and PFOA from biosolids-amended soils}

Earthworms were exposed to a $1000 \mathrm{~mL}$ polypropylene beaker containing $1 \mathrm{~kg}$ of biosolids-amended soils (Nos. 1-7). Autoclaved distilled water was added to give a moisture content of $40 \%$ water holding capacity (WHC). There were 33 beakers for each soil and each beaker held ten earthworms. Earthworms were randomly sampled after $0,2,5,7,13,20$ and $30 \mathrm{~d}$ to study the uptake kinetics. Remaining earthworms were then transferred into beakers containing uncontaminated soils, and were randomly sampled after $32,35,43,50$ and $60 \mathrm{~d}$ to study the excretion kinetics. Three replicates were carried out for each time point. The collected earthworms were placed in wet filter paper for $12 \mathrm{~h}$ to allow the gut to empty. Initial experiments indicated no difference in earthworm PFOA and PFOS body burdens after 12 or $24 \mathrm{~h}$ of depuration. After $12 \mathrm{~h}$, the earthworms were transferred and rinsed with distilled water, wiped with clean towel paper, weighed and frozen at $20 \pm 1^{\circ} \mathrm{C}$ for $24 \mathrm{~h}$. Earthworms cultured in uncontaminated soil was used as control. Then the earthworms were freeze-dried, weighed again, ground and stored at $-20 \pm 1{ }^{\circ} \mathrm{C}$ before chemical analysis. Results obtained by our preliminary study showed that PFOA and PFOS losses caused by freeze drying are neglectable.

The concentrations of PFOS and PFOA in the earthworms were expressed as ng ${ }^{-1}$ dry weight and corrected for the earthworm weight changes during the exposure time. Triplicate tests were used for statistical analysis of PFOS and PFOA uptake and elimination kinetics.

\subsection{Determination of PFOS and PFOA in soils and earthworms}

PFOS and PFOA in soils were extracted by MTBE-NaOH according to the method of Wen et al. (2014). PFOS and PFOA in earthworms were extracted by $\mathrm{MeOH}-\mathrm{NaOH}$ according to the method of Zhao et al. (2013). The two extraction methods and purification were detailed in the Supplementary materials.

An ultra performance liquid chromatography-tandem mass spectrometry (UPLC-MS/MS) was used to determine the concentrations of PFOS and PFOA. The UPLC system (ACQUITY, Waters Corp., USA) was equipped with a UPLC BEH C18 column $(2.1 \times 150 \mathrm{~mm}, 1.7 \mu \mathrm{m}$, Waters Corp., USA $)$ that was maintained at $40{ }^{\circ} \mathrm{C}$ in column oven. The Quattro Premier XE tandem quadrupole mass spectrometer (Waters Corp., USA) was equipped with an electrospray ionization source. The mixture of acetonitrile/ $10 \mathrm{mmol} \mathrm{L}^{-1}$ ammonium acetate $(50 / 50, \mathrm{v} / \mathrm{v})$ was used as mobile phase at a flow rate of $0.2 \mathrm{~mL} \mathrm{~min}^{-1}$. The MS/MS was operated in electrospray negative ionization mode. The collision energies, cone voltages and MS/MS parameters for the instrument were optimized for individual analytes (Table S2). 


\subsection{Quality assurance and quality control}

Quality control was done by regular analyses of procedural blanks, blind duplicate samples, and random injection of solvent blanks and standards. Blank matrix was obtained from uncontaminated soils and earthworms cultured in uncontaminated soils. Matrix calibration curves using spiked uncontaminated samples that were extracted in analogy to the samples were applied for quantification. An eighteen-point calibration line was used for quantification. The fitted lines had $r^{2}$ values of at least 0.99 for all analytes.

The method-detection limits (MDLs) were defined as the concentration corresponding to the mean peak area plus three standard deviations $(x+3 \sigma)$ of extract from uncontaminated soil and earthworms incubated in the uncontaminated soil. The limits of quantitation (LOQs) were defined as the concentration corresponding to the mean peak area plus ten standard deviations $(x+10 \sigma)$ of extract from uncontaminated soil and earthworms incubated in the uncontaminated soil (Yoo et al., 2011). MDLs and LOQs were measured for each matrix on replicate analyses $(n=6)$ (Table S2). All samples were injected in triplicate. The accuracy of PFOS and PFOA determination was assessed by testing the recoveries of ${ }^{13} \mathrm{C}_{4}$-PFOS and ${ }^{13} \mathrm{C}_{4}$-PFOA. The recoveries of ${ }^{13} \mathrm{C}_{4}$-PFOS and ${ }^{13} \mathrm{C}_{4}$-PFOA were $92-105 \%$ and $89-103 \%$, respectively for soils, and $81-101 \%$ and $78-95 \%$, respectively for earthworms.

\subsection{Modeling}

In this experiment, the masses of the earthworms were measured. The concentrations of PFOS and PFOA in the earthworms were expressed as ng g $^{-1}$ dry weight and corrected for the earthworm mass changes during the exposure experiment. Triplicate tests were used for statistical analysis of PFOS and PFOA accumulation kinetics. It was shown that accumulation of organic pollutants by earthworms can be described by a one-compartment model (Wen et al., 2011). To model PFOS and PFOA accumulation and calculate their uptake and elimination rates over both the uptake and elimination phases of the experiment, the experimental data were fitted with Eqs. (1) and (2) below:

$Q_{\mathrm{t}}=Q_{0}+\alpha / k_{\mathrm{e}}\left(1-e^{-k_{\mathrm{e}} t}\right)$

where $Q_{t}$ is the total concentrations of PFOS and/or PFOA ( $\mathrm{ng} \mathrm{g}_{\text {worm }}^{-1}$ ) in earthworms at time $t(\mathrm{~d}), k_{\mathrm{e}}$ is the elimination rate constant $\left(\mathrm{d}^{-1}\right)$, and $\alpha$ is the uptake flux constant $\left(\mathrm{ng} \mathrm{g}_{\text {worm }}^{-1} \mathrm{~d}^{-1}\right.$ ), which equals to $k_{\mathrm{u}} C_{\text {soil }}$, where $k_{\mathrm{u}}$ is the uptake rate constant $\left(\mathrm{g}_{\text {soil }} \mathrm{g}_{\text {worm }}^{-1} \mathrm{~d}^{-1}\right)$ and $C_{\text {soil }}$ is the PFOS or PFOA concentrations in soils ( $\mathrm{ng} \mathrm{g}_{\text {soil }}^{-1}$ ). The concentration of PFOS or PFOA in earthworms at the beginning of the experiment, $Q_{0}$, was assumed to be a pool of constant magnitude.

Once transferred to uncontaminated soil, PFOS or PFOA concentrations in earthworms varied with time according to the following equation:

$Q_{\mathrm{t}}=Q_{\mathrm{e}}+\left(Q_{\mathrm{tc}}-Q_{\mathrm{e}}\right) e^{-k_{\mathrm{e}}\left(t-t_{\mathrm{c}}\right)}$

where $Q_{e}$ is the residue concentrations of PFOS or PFOA in earthworms ( $\mathrm{ng} \mathrm{g}_{\text {worm }}^{-1}$ ) at the end of the elimination period (day 60) and $Q_{\mathrm{tc}}$ is the PFOS or PFOA concentrations in earthworms ( $\mathrm{ng} \mathrm{g}_{\text {worm }}^{-1}$ ) at the end of the accumulation period (day 30 ). $t_{\mathrm{c}}$ is the time (d) at which earthworms were transferred to the clean pot, and $t$ is the time (d) since the beginning of the experiment. Subsequently, Eq. (1) was used to calculate steady-state tissue PFOS and PFOA concentrations $\left(C_{\mathrm{ss}}\right)$ for earthworms, and time to reach $90 \%$ of the steady state concentration $\left(t_{\mathrm{ss}}\right)$ :

$C_{\mathrm{ss}}=\alpha / k_{\mathrm{e}}$

$t_{\mathrm{ss}}=-1 / k_{\mathrm{e}} \ln (1-90 \%)$
The steady-state concentrations were used to calculate bioaccumulation factors (the ratio of the PFOS or PFOA concentrations in earthworms to those in soils, BAF).

\subsection{Data analysis}

All statistical analyses were conducted with the software SPSS 11.5 for Windows (SPSS Inc., Chicago, IL). Linear and nonlinear regression analyses were conducted by the least and least-squares methods, respectively. A stepwise multiple linear regression technique was used to derive the relationship among variables. Statements of significant differences are based on $P<0.05$.

\section{Results and discussion}

\subsection{Concentrations of PFOA and PFOS in soils}

The concentrations of PFOS and PFOA in uncontaminated soil are below their MDL levels. The properties and concentrations of PFOA and PFOS in biosolids-amended soils are given in Table S1. All soils are alkaline, with soil $\mathrm{pH}$ ranging from 7.36 to 8.43 . The organic matter contents varied from $1.38 \%$ to $3.90 \%$. The PFOS and PFOA contents ranged 1.44-43.2 $\mathrm{ng} \mathrm{g}^{-1}$, and $1.21-28.5 \mathrm{ng} \mathrm{g}^{-1}$, respectively. The PFOS and PFOA concentrations in the soils sampled from the same site increased with increasing OM contents. For example, significant correlation was found between PFOA concentrations in soils sampled from Changping and their OM contents $(P<0.05$, Fig. S1), suggesting that land application of biosolids not only increases the OM contents, but also results in the accumulation of PFASs in soils.

\subsection{Uptake and elimination kinetics}

During the $60 \mathrm{~d}$ experiment period, all earthworms had a healthy appearance, and no mortality occurred. The average wet weight loss was from $15 \%$ to $40 \%$, with varying time. No significant difference of weight losses was found between earthworms exposed in biosolid-amended soils and in uncontaminated control soil. The initial concentrations of PFOA and PFOS in earthworms were under their MDLs.

During the exposure phase, the uptake of PFOA and PFOS by earthworms was nonlinear (Fig. 1). Tissue PFOS and PFOA concentrations showed an initial rapid increase in the first 7 days followed by a leveling off. Uptake saturation was reached within the 30 days. On the day 30 , the PFOS concentrations in the earthworms were $\quad 5.90 \pm 0.60, \quad 36.1 \pm 2.3, \quad 51.2 \pm 2.9, \quad 79.9 \pm 3.3, \quad 129 \pm 8$, $96.6 \pm 8.2$ and $66.6 \pm 6.6 \mathrm{ng} \mathrm{g}^{-1}$, respectively, while PFOA concentrations in the earthworms were $1.60 \pm 0.14,4.9 \pm 0.1,13.3 \pm 2.2$, $18.2 \pm 1.1,22.8 \pm 1.1,22.2 \pm 1.0$ and $14.8 \pm 1.2 \mathrm{ng} \mathrm{g}^{-1}$, respectively, for the seven soils (Nos. 1-7). During the $30 \mathrm{~d}$ depuration period, the concentrations of PFOA and PFOS in earthworms decreased gradually. About $90 \%$ PFOS and PFOA were lost at the end of the elimination experiment.

The individual uptake and elimination data of PFOS and PFOA fitted well with Eqs. (1) and (2), respectively, with high $R^{2}$ values $(>0.98)$ and low mean weighted square errors (MWSE; Fig. 1, Table 1). The $k_{\mathrm{e}}$ values calculated from Eq. (1) were consistent with those calculated from Eq. (2), confirming the validity of the estimation. The calculated steady-state tissue concentrations $\left(C_{\mathrm{ss}}\right)$ of PFOS and PFOA were in the range of those determined at the end of uptake period (day 30). Liu et al. (2011) found the discrepancy between the kinetic and the steady-state approaches for the accumulation of PFASs in green mussel (Perna viridis), and suggested that the first order uptake reaction was inappropriate in the case of PFASs bioaccumulation. However, Zhao et al. (2013) found that 

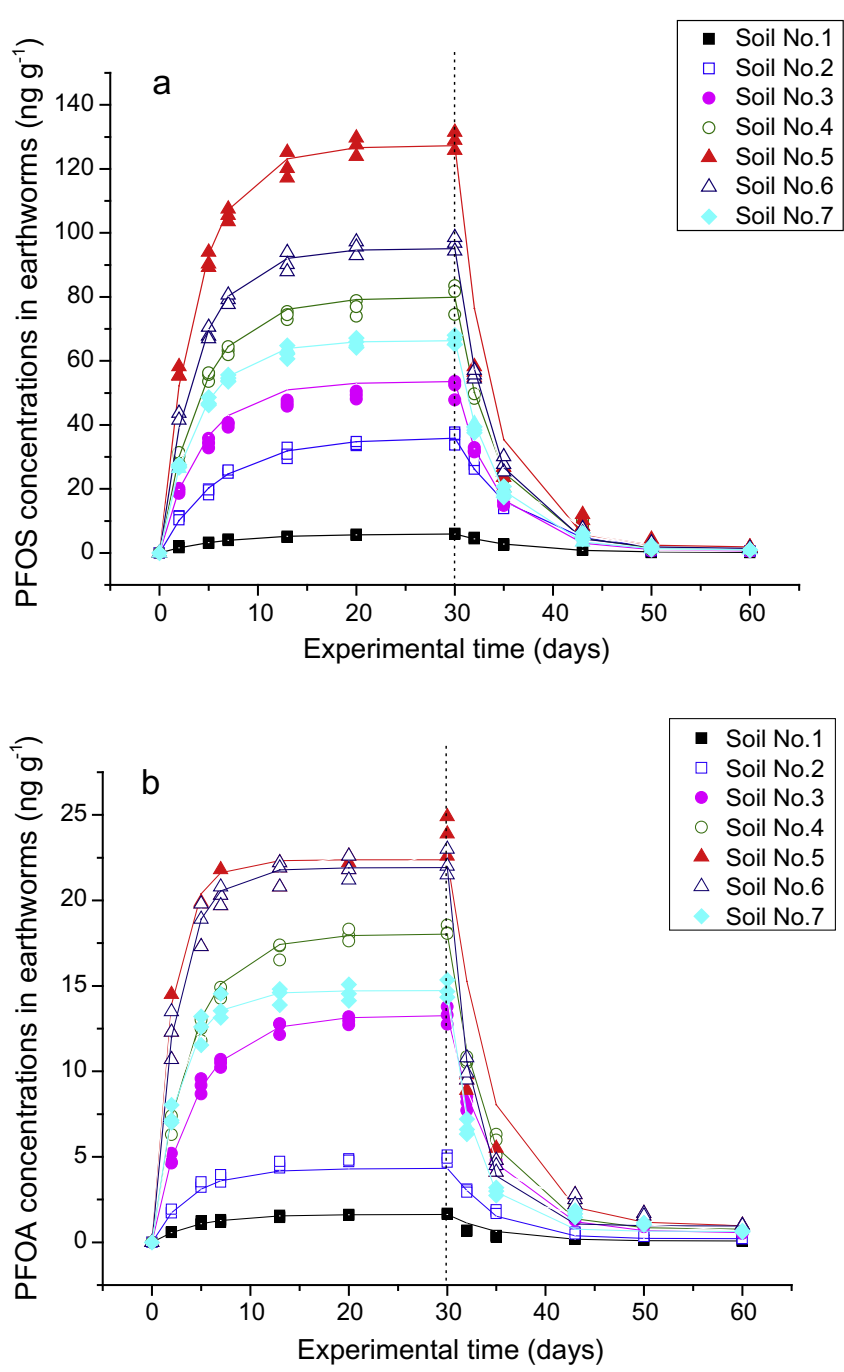

Fig. 1. Accumulation and elimination kinetics of PFOS (a) and PFOA (b) in soils (Nos. 1-7). Dots: experimental data. Lines: fits to Eqs. (1) and (2) for the uptake and elimination, respectively.

the first order kinetics could be used to describe the earthworm accumulation of PFASs from contaminated soil well, which was consistent with our results. The estimated $k_{\mathrm{u}}$ values ranged from 0.379 to $0.823 \mathrm{~g}_{\text {soil }} \mathrm{g}_{\text {worm }}^{-1} \mathrm{~d}^{-1}$ for PFOS, and from 0.293 to $0.416 \mathrm{~g}_{\text {soil }} \mathrm{g}_{\text {worm }}^{-1} \mathrm{~d}^{-1}$ for PFOA, while the $k_{\mathrm{e}}$ values ranged from 0.158 to $0.265 \mathrm{~d}^{-1}$ for PFOS, and from 0.216 to $0.363 \mathrm{~d}^{-1}$ for PFOA. For PFOS and PFOA in soil No. 1, whose PFOS and PFOA concentrations were similar (Table S1), PFOS displayed higher $k_{\mathrm{u}}$ and lower $k_{\mathrm{e}}$ values than those of PFOA. This revealed that PFOS was taken up at a higher rate whereas depurated at a lower rate than PFOA. The higher $k_{\mathrm{u}}$ and the lower $k_{\mathrm{e}}$ values resulted in a relative higher steady-state tissue PFOS concentration $\left(C_{\mathrm{ss}}\right)$ and bioaccumulation factor (BAF). The BAF values of PFOS were in the range of 1.544.12, which were higher than those of PFOA (0.516-1.36). These results of high BAF values of PFOS are in accordance with what reported by Zhao et al. (2013), in which bioaccumulation kinetics of PFASs in earthworms exposed in lab-contaminated water or soils were investigated. Bioaccumulation of PFASs was believed to be related with their fluorinated carbon chain length and ionic functional groups for both aquatic and terrestrial organisms. The BAF values of PFASs increased with the increase of fluorinated carbon chain length. The fluorinated carbon length of PFOS was longer than that of PFOA. In addition, the binding affinity by sulfonate was higher than carboxylate with the same fluorinated perfluorinated chain (Martin et al., 2003; Woodcroft et al., 2010; Liu et al., 2011; Zhao et al., 2013).

Among the soils studied, the concentrations of PFOS and PFOA in soil No. 1 were the lowest, while the $t_{\mathrm{ss}}$ and BAF values of soil No. 1 were the highest (Table 1). This indicates that uptake kinetics of PFOS and PFOA may be affected by their soil concentrations. In order to further assess the concentration effect, relationship between the soil PFOS and/or PFOA concentrations and their uptake kinetic parameters were investigated. No significant relationship between PFOS and/or PFOA concentrations in the soils and the $k_{\mathrm{u}}$ values was found (data not shown), while soil concentrations of PFOS and/or PFOA correlated positively with the $k_{\mathrm{e}}$ values, and thus correlated negatively with the $t_{\mathrm{ss}}(P<0.05$, Fig. S2a-d). A similar significantly negative relationship was found between soil PFOS and/or PFOA concentrations and BAF values $(P<0.05$, Fig. S2e and $f)$. This suggests that the time to reach steady state and the bioaccumulation factor decrease with the increase of soil PFAS concentrations. Such phenomena of the concentrationdependent BAF values of PFASs were observed by Giesy et al. (2010) and Zhao et al. (2013). Also Liu et al. (2011) reported that not only the BAF but also the $t_{\mathrm{ss}}$ values of PFASs in green mussels decreased with the increasing exposure concentration. It is recognized that lipid is not the bioaccumulation compartment for PFASs

Table 1

Estimates of kinetic parameters for PFOS and PFOA uptake and elimination.

\begin{tabular}{|c|c|c|c|c|c|c|c|c|c|c|c|}
\hline \multirow[t]{2}{*}{ Soils } & \multicolumn{8}{|c|}{ Calculated from Eq. (1) } & \multicolumn{3}{|c|}{ Calculated from Eq. (2) } \\
\hline & $\alpha\left(\right.$ ng g gorm $\left._{\text {wor }}^{-1} \mathrm{~d}^{-1}\right)$ & $\left.k_{\mathrm{u}\left(\mathrm{g}_{\text {soil }}\right.} \mathrm{g}_{\text {worm }}^{-1} \mathrm{~d}^{-1}\right)$ & $k_{\mathrm{e}}\left(\mathrm{d}^{-1}\right)$ & $C_{\mathrm{ss}}\left(\mathrm{ng} \mathrm{g}_{\text {worm }}^{-1}\right)$ & $t_{\mathrm{ss}}(\mathrm{d})$ & BAF & $R^{2}$ & MWSE $^{\mathrm{a}}$ & $k_{\mathrm{e}}\left(\mathrm{d}^{-1}\right)$ & $R^{2}$ & $\overline{\text { MWSE }}$ \\
\hline \multicolumn{12}{|l|}{ PFOS } \\
\hline No. 1 & $0.938(0.050)$ & 0.379 & $0.158(0.009)$ & 5.94 & 14.6 & 4.12 & 0.996 & 0.012 & $0.160(0.006)$ & 0.992 & 0.103 \\
\hline No. 2 & $5.96(0.23)$ & 0.573 & $0.165(0.008)$ & 36.1 & 14.0 & 3.47 & 0.991 & 0.004 & $0.162(0.007)$ & 0.991 & 0.178 \\
\hline No. 3 & $11.8(0.4)$ & 0.769 & $0.231(0.009)$ & 51.3 & 9.97 & 3.33 & 0.994 & 0.005 & $0.231(0.009)$ & 0.993 & 0.147 \\
\hline No. 4 & $18.9(0.8)$ & 0.666 & $0.236(0.009)$ & 79.5 & 9.76 & 2.82 & 0.994 & 0.002 & $0.239(0.009)$ & 0.990 & 0.175 \\
\hline No. 5 & $33.6(0.9)$ & 0.823 & $0.264(0.011)$ & 127 & 8.72 & 3.12 & 0.995 & 0.002 & $0.266(0.014)$ & 0.997 & 0.097 \\
\hline No. 6 & $25.2(0.7)$ & 0.600 & $0.265(0.009)$ & 95.1 & 8.69 & 2.26 & 0.995 & 0.002 & $0.263(0.007)$ & 0.997 & 0.092 \\
\hline No. 7 & $16.9(0.4)$ & 0.390 & $0.254(0.007)$ & 66.3 & 9.07 & 1.54 & 0.997 & 0.001 & $0.262(0.007)$ & 0.997 & 0.098 \\
\hline \multicolumn{12}{|l|}{ PFOA } \\
\hline No. 1 & $0.355(0.016)$ & 0.293 & $0.216(0.012)$ & 1.64 & 10.7 & 1.36 & 0.995 & 0.045 & $0.208(0.008)$ & 0.988 & 0.088 \\
\hline No. 2 & $1.10(0.04)$ & 0.254 & $0.224(0.009)$ & 4.91 & 10.3 & 1.14 & 0.995 & 0.011 & $0.227(0.007)$ & 0.995 & 0.096 \\
\hline No. 3 & $3.04(0.08)$ & 0.241 & $0.229(0.007)$ & 13.3 & 10.1 & 1.05 & 0.996 & 0.001 & $0.229(0.008)$ & 0.996 & 0.041 \\
\hline No. 4 & $4.69(0.10)$ & 0.233 & $0.260(0.006)$ & 18.1 & 9.84 & 0.913 & 0.997 & 0.003 & $0.258(0.008)$ & 0.995 & 0.085 \\
\hline No. 5 & $10.9(1.0)$ & 0.416 & $0.485(0.049)$ & 22.4 & 4.75 & 0.857 & 0.986 & 0.008 & $0.414(0.027)$ & 0.986 & 0.105 \\
\hline No. 6 & $8.69(0.43)$ & 0.317 & $0.397(0.022)$ & 21.9 & 5.80 & 0.799 & 0.989 & 0.003 & $0.394(0.019)$ & 0.988 & 0.096 \\
\hline No. 7 & $5.34(0.24)$ & 0.187 & $0.363(0.018)$ & 14.7 & 6.34 & 0.516 & 0.991 & 0.001 & $0.364(0.018)$ & 0.990 & 0.085 \\
\hline
\end{tabular}

${ }^{\text {a }}$ Mean weighted square error, equal to $1 / \gamma \Sigma\left[\left(q_{\text {measured }}-q_{\text {model }}\right)^{2} / q_{\text {measured }}^{2}\right.$, where $\gamma$ is the amount of freedom; $\gamma=N-2$ for Eq. (1), while $\gamma=N-1$ for Eq. (2). 
Table 2

The stepwise multiple linear regression equations for PFOS and PFOA in earthworms as function of their concentrations in soils and soil characteristics.

\begin{tabular}{|c|c|c|c|c|}
\hline & Multiple linear equation & $R^{2}$ & $P$ & S.E. \\
\hline \multicolumn{5}{|c|}{ The stepwise regression for PFOS } \\
\hline 1 & {$[\mathrm{PFOS}]_{\text {worm }}=2.045[\mathrm{PFOS}]_{\text {Soil }}+13.323$} & 0.696 & 0.012 & 22.2 \\
\hline 2 & {$[\mathrm{PFOS}]_{\text {worm }}=4.439[\mathrm{PFOS}]_{\text {Soil }}-47.483[\mathrm{OM}]+70.629$} & 0.872 & 0.007 & 14.4 \\
\hline \multicolumn{5}{|c|}{ The stepwise regression for $P F O A$} \\
\hline 1 & {$[\mathrm{PFOA}]_{\text {worm }}=0.658[\mathrm{PFOA}]_{\text {Soil }}+2.678$} & 0.792 & 0.005 & 3.72 \\
\hline 2 & {$[\mathrm{PFOA}]_{\text {worm }}=1.382[\mathrm{PFOA}]_{\text {Soil }}-9.300[\mathrm{OM}]+13.655$} & 0.913 & 0.003 & 2.41 \\
\hline
\end{tabular}

even though a portion of PFAS molecules is hydrophobic and may interact with lipid (Zhao et al., 2013). Bioaccumulation of PFASs is an adsorption-like process. The adsorption sites are likely some proteins in bioorganism, which could strongly bind with PFASs (Washington et al., 2010; Bischel et al., 2010; Han et al., 2012). Desorption rates of PFASs from these proteins may be slower than those from lipid. These adsorption sites are occupied and gradually saturated with PFAS concentration increasing. Alternatively, the concentration-dependent BAF values of PFOS and PFOA may be due to their resistant desorption at high concentrations. When Sormunen et al. (2008) studied the desorption and bioavailability of 3,3',4,4'-tetrachlorobiphenyl (PCB 77), they found that the rapid-desorbing fractions and the biota-sediment accumulation factor of PCB 77 decreased with increasing concentration in sediment. Although the desorption resistance for PFOS and PFOA from sediments and humic acid was reported (Pan et al., 2009; Jia et al., 2010), further studies are necessary to assess the concentration-dependent effects on the desorption and bioavailability of PFASs.

\subsection{Quantification of the relationship between PFAS accumulation and soil properties}

Earthworms may take up contaminants from soil and porewater, both through their skin (dermal) and by ingestion (oral). It is assumed that only contaminants that can be released from soil/sediment are available to biological receptors. Qi and Chen (2010) suggested that for readily desorbable contaminants, the primary biouptake route is the porewater uptake. But for the desorption-resistant contaminants, the uptake from ingested soil particles can be also important. It remains unclear what the relative important pathways for PFASs accumulation by earthworm is, however, the importance of porewater uptake is estimated based on their high water solubility when compared with those of PAHs and PBDEs. The PFAS concentrations in porewater depend on their soil concentrations and soil properties. It has been reported that organic carbon is the most important parameter dominating PFOS sorption (Higgins and Luthy, 2006; Johnson et al., 2007; Jia et al., 2010). In addition, pH, sand and clay contents play roles in PFOS retention (Higgins and Luthy, 2006; Johnson et al., 2007). Considering the multi-contributions of various soil properties, including soil $\mathrm{pH}$, organic matter and clay content, it is expected that multi linear regression model would quantify the bioaccumulation of PFOS and PFOA by earthworms. Based on the stepwise regressions, the best regression models describing the relationship between PFOS and PFOA concentrations in earthworm tissues and their concentrations in the soils and soil properties were obtained (Table 2). The results verified that the soil PFOS and PFOA concentrations and soil OM content ([OM]) are two key factors controlling the bioavailability of PFOS and PFOA in soils. Specifically, PFOS concentration in soil $\left([\mathrm{PFOS}]_{\text {soil }}\right)$ was the first independent variable fitted to the PFOS concentrations in earthworm ([PFOS $\left.]_{\text {worm }}\right)$ and could explain $69.6 \%(P<0.05)$ of the variability in $[\mathrm{PFOS}]_{\text {worm. }}$. Including $\mathrm{OM}$ content as a predictor (explanatory variables) improved the model fitting to $87.2 \%$ $(P<0.01)$. Other soil properties, such as $\mathrm{pH}, \mathrm{CEC}$, sand, silt and clay contents, did not improve the model fitting. This suggests that PFOS concentration in soil and soil organic carbon content dominant the accumulation of PFOS in earthworm. Similarly, PFOA concentration in soil $\left([\mathrm{PFOA}]_{\text {soil }}\right)$ could explain $79.2 \%$ of the variability in PFOA concentration in earthworm ([PFOA $\left.]_{\text {worm }}\right)$, and including OM content as a predictor improved the model to 91.3\%. Soil properties other than OM content as factors could not improve the model fitting. These suggested that soil concentration and OM content dominated the bioavailability of PFASs in soils. Soil $\mathrm{pH}$ and clay content appeared relatively unimportant for PFOS and PFOA bioavailability.

\section{Conclusion}

The results of this study demonstrated that contamination of PFOS and PFOA in soils as a result of biosolids land application led to accumulation of PFOS and PFOA in earthworms with higher concentration of PFOS than that of PFOA. The finding that the BAFs decreased with increase of PFOS and PFOA concentrations in soils indicated that the uptake of PFOS and PFOA by earthworms from biosolids-amended soil may not be a process of partitioning equilibrium. Soil PFOS and PFOA concentration and soil organic carbon content can act as better predictors of bioavailable PFOS and PFOA in biosolids-amended soils than soil $\mathrm{pH}$ and clay content. Current findings would help understand the bioavailability of PFASs in soils and assess the risks of PFASs in soils as a result of biosolids application.

\section{Acknowledgements}

This work was funded by the Strategic Priority Research Program of the Chinese Academy of Sciences (XDB14020202), the National Key Basic Research Program of China (973 Program) (Grant No. 2014CB441102), and the National Natural Science Foundation of China (Project 41371460).

\section{Appendix A. Supplementary material}

Supplementary data associated with this article can be found, in the online version, at http://dx.doi.org/10.1016/j.chemosphere. 2014.08.009.

\section{References}

Bischel, H.N., Macmanus-Spencer, L.A., Luthy, R.G., 2010. Noncovalent interactions of long-chain perfluoroalkyl acids with serum albumin. Environ. Sci. Technol. 44, 5263-5269.

Clarke, B.O., Smith, S.R., 2011. Review of 'emerging' organic contaminants in biosolids and assessment of international research priorities for the agricultural use of biosolids. Environ. Int. 37, 226-247.

Giesy, J.P., Naile, J.E., Khim, J.S., Jones, P.D., Newsted, J.L., 2010. Aquatic toxicology of perfluorinated chemicals. Rev. Environ. Contam. Toxicol. 202, 1-52.

Gomez-Eyles, J.L., Sizmur, T., Collins, C.D., Hodson, M.E., 2011. Effects of biochar and the earthworm Eisenia fetida on the bioavailability of polycyclic aromatic hydrocarbons and potentially toxic elements. Environ. Pollut. 159, 616-622. 
Han, X., Nabb, D.L., Russell, M.H., Kennedy, G.L., Rickard, R.W., 2012. Renal elimination of perfluorocarboxylates (PFCAs). Chem. Res. Toxicol. 25, 35-46.

Higgins, C.P., Field, J.A., Criddle, C.S., Luthy, R.G., 2005. Quantitative determination of perfluorochemicals in sediments and domestic sludge. Environ. Sci. Technol. 39, 3946-3956.

Higgins, C.P., Luthy, R.G., 2006. Sorption of perfluorinated surfactants on sediments. Environ. Sci. Technol. 40, 7251-7256.

Houde, M., De Silva, A.O., Muir, D.C.G., Letcher, R.J., 2011. Monitoring of perfluorinated compounds in aquatic biota: an updated review, PFCs in aquatic biota. Environ. Sci. Technol. 45, 7962-7973.

Hu, J.Y., Tanaka, S., Fujii, S., 2011. Perfluorooctane sulfonate (PFOS) and perfluorooctanoic acid (PFOA) in water environment of Singapore. Water Air Soil Pollut. 216, 179-191.

Jia, C.X., You, C., Pan, G., 2010. Effect of temperature on the sorption and desorption of perfluorooctane sulfonate on humic acid. J. Environ. Sci. 22, 355-361.

Johnson, R.L., Anschutz, A.J., Smolen, J.M., Simcik, M.F., Penn, R.L., 2007. The adsorption of perfluorooctane sulfonate onto sand, clay, and iron oxide surfaces. J. Chem. Eng. Data 52, 1165-1170.

Liang, X.W., Zhu, S.Z., Chen, P., Zhu, L.Y., 2010. Bioaccumulation and bioavailability of polybrominated diphynel ethers (PBDEs) in soil. Environ. Pollut. 158, 2387-2392.

Li, J., Vento, S.D., Schuster, J., Zhang, G., Chakraborty, P., Kobara, Y., Jones, D.C., 2011. Perfluorinated compounds in the Asian atmosphere. Environ. Sci. Technol. 45, $7241-7248$.

Liu, C.H., Gin, K.Y.H., Chang, V.W.C., Goh, B.P.L., Martin, R., 2011. Novel perspective on the bioaccumulation of PFCs - the concentration dependency. Environ. Sci. Technol. 45, 9758-9764.

Martin, J.W., Mabury, S.A., Solomon, K.R., Muir, D.C.G., 2003. Bioconcentrations and tissue distribution of ferfluorinated acids in rainbow trout (Oncorhynchus Mykiss). Environ. Toxicol. Chem. 22, 196-204.

Müller, C.E., De Silva, A.O., Small, J., Williamson, M., Wang, X., Morris, A., Katz, S. 2011. Biomagnification of perfluorinated compounds in a remote terrestrial food chain: lichen-caribou-wolf. Environ. Sci. Technol. 45, 8665-8673.

Nelson, D.W., Sommers, D., 1982. Total carbon, organic carbon, and organic matter. In: Page, A.L. et al. (Eds.), Methods of Soil Analysis: Total Carbon, Organic Carbon, and Organic Matter, Part 2, second ed. ASA and SSSA, Madison, WI, pp. 539-579.

Pan, G., Jia, C.X., Zhao, D.Y., You, C., Chen, H., Jiang, G.B., 2009. Effect of cationic and anionic surfactants on the sorption and desorptin of perfluorooctane sulfonate (PFOS) on natural sediment. Environ. Pollut. 157, 325-330.

Qi, Y., Chen, W., 2010. Comparison of earthworm bioaccumulation between readily desorbable and desorption-resistant naphthalene: implications for biouptake routes. Environ. Sci. Technol. 44, 323-328.
Rhoades, J.D., 1982. Cation-exchange capacity. In: Page, A.L. (Ed.), Methods of Soil Analysis, Part 2, second ed. American Society of Agronomy, Madison, WI, pp. 149-158.

Sepulvado, J.G., Blaine, A.C., Hundal, L.S., Higgins, C.P., 2011. Occurrence and fate of perfluorochemicals in soil following the land application of municipal biosolids Environ. Sci. Technol. 45, 8106-8112.

Sormunen, A.J., Nen, M.T.L., Kukkonen, J.V.K., 2008. Influence of sediment ingestion and exposure concentration on the bioavailable fraction of sediment-associated tetrachlorobiphenyl in oligochaetes. Environ. Toxicol. Chem. 27, 854-863.

Sun, H., Gerecke, A.C., Giger, W., Alder, A.C., 2011. Long-chain perfluorinated chemicals in digested sewage sledges in Switzerland. Environ. Pollut. 159, 654 662.

Washington, J.W., Yoo, H., Ellington, J.J., Jenkins, T.M., Libelo, E.L., 2010. Concentrations, distribution, and persistence of perfluoroalkylates in sludge-applied soils near Decatur, Alabama, USA. Environ. Sci. Technol. 44, 8390-8396.

Wen, B., Huang, R.X., Wang, P., Zhou, Y.P., Shan, X.Q., Zhang, S.Z., 2011. Effect of complexation on the accumulation and elimination kinetics of cadmium and ciprofloxacin in the earthworm Eisenia fetida. Environ. Sci. Technol. 45, 43394345.

Wen, B., Li, L.F., Zhang, H.N., Ma, Y.B., Shan, X.Q., Zhang, S.Z., 2014. Field study on the uptake and translocation of perfluoroalkyl acids (PFAAs) by wheat (Triticum aestivum L.) grown in biosolids-amended soils. Environ. Pollut. 184, 547-554.

Woodcroft, M.W., Ellis, D.A., Rafferty, S.P., Burns, D.C., March, R.E., Stock, N.L. Trumpour, K.S., Yee, J., Munro, K., 2010. Experimental characterization of the mechanism of perfluorocarboxylic acids' liver protein bioaccumulation: the key role of the neutral species. Environ. Toxicol. Chem. 29, 1669-1677.

Yoo, H., Washington, J.W., Ellington, J.J., Jenkins, T.M., Neill, M.P., 2010 Concentrations, distribution, and persistence of fluorotelomer alcohols in sludge-applied soils near Decatur, Alabama, USA. Environ. Sci. Technol. 44 8397-8402.

Yoo, H., Washington, J.W., Jenkins, T.M., Ellington, J.J., 2011. Quantitative determination of perfluorochemicals and fluorotelomer alcohols in plants from biosolid-amended fields using LC/MS/MS and GC/MS. Environ. Sci. Technol. 45, 7985-7990.

Zhao, S.Y., Zhu, L.Y., Liu, L., Liu, Z.T., Zhang, Y.H., 2013. Bioaccumulation of perfluoroalkyl carboxylates (PFCAs) and perfluoroalkane sulfonates (PFSAs) by earthworms (Eisenia fetida) in soil. Environ. Pollut. 179, 45-52.

Zhao, S.Y., Fang, S.H., Zhu, L.Y., Liu, L., Liu, Z.T., Zhang, Y.H., 2014. Mutual Impacts of Wheat (Triticum aestivum L.) and Earthworms (Eisenia fetida) on the Bioavailability of Perfluoroalkyl substances (PFASs) in Soil. Environ. Pollut. 184, 495-501. 